\title{
Focus on adequate antimicrobial treatment and de-escalation in the ICU
}

\author{
Dominique D. Benoit ${ }^{1 *}$, Gordon Doig ${ }^{2}$ and Jean-Francois Timsit ${ }^{3}$
}

C 2016 Springer-Verlag Berlin Heidelberg and ESICM

Adequate antimicrobial treatment is considered of upmost importance to reduce mortality in critically ill patients with infection. However, because of the dramatic increase of antibiotic resistance worldwide [1,2] and the delay in microbiological identification of pathogens, adequate antibiotic treatment is more easy to define retrospectively on chart review than to implement prospectively at the bedside. Several articles recently published in Intensive Care Medicine have provided some clues in how to improve adequate antimicrobial treatment in daily practice.

The concept of adequate antimicrobial therapy was defined as an extension of "appropriate antimicrobial therapy" which necessitates that the causative pathogen is susceptible to the antibiotic regimen and that this regimen is initiated early at optimized dose and dose intervals [3]. The most critical step in our opinion is the first one because the delay in microbiological documentation forces clinicians to outweigh the chances of potentially harming an individual in favor of the community. Instead of choosing the more difficult probabilistic focused approach, many clinicians in previous decades opted for the easier more trivial approach of prescribing broad-spectrum antibiotics in any circumstances [1]. Experts in the field therefore nowadays only recommend prescribing an empiric antibiotic regimen targeting the most likely pathogen(s) based on local epidemiology in patients at risk of multidrug-resistant pathogens or with severe sepsis [3, 4]. Despite the low level of evidence in both non-neutropenic [5] and neutropenic patients with sepsis [6], combination antibiotic treatment continues to be recommended, mainly because it increases the

\footnotetext{
*Correspondence: dominique.benoit@ugent.be

1 Department of Intensive Care, Ghent University Hospital, Ghent, Belgium

Full author information is available at the end of the article
}

spectrum of antimicrobials, with the hope of maximizing clinical efficacy and preventing the development of resistance [3]. With regards to gram-negative pathogens, this is most often achieved by combining a $\beta$-lactam antibiotic with an aminoglycoside [3]. Although widely used, fluoroquinolones are less recommended in this setting [7] because of the potential ecological consequences [8]. The use of a carbapenem should mainly be considered in hospital-acquired infections or in patients with a previous history or colonization in the last 3 months by extended-spectrum $\beta$-lactamase-producing Enterobacteriaceae or by ceftazidime-resistant Pseudomonas aeruginosa presenting with severe sepsis or septic shock [7]. The probability of harming a patient using this threshold is indeed very low since the median duration of colonization with highly resistant Enterobacteriaceae was 1.4 months among 101 episodes according to a recent study by Haverkate et al. [9].

Achieving adequate concentrations of $\beta$-lactam antibiotics or aminoglycosides in critically ill patients is not easy. De Montmollin et al. found that the pharmacodynamic target for less susceptible bacteria could be attained in only $33 \%$ of the 181 sepsis episodes despite a dosing regimen of $25 \mathrm{mg} / \mathrm{kg}$ of amikacin [10]. Using data from the DALI point-prevalence study [11], De Waele et al. found that, using empirical dosing and considering a worst-case scenario, 19 and $41 \%$ of the 343 critically ill patients included in the study would not achieve $\beta$-lactam concentrations above the minimal inhibitory concentration during 50 and $100 \%$ of the interval, respectively [12]. The use of bolus infusion (as compared to extended and continuous infusion) was the main determinant of non-attainment for both targets, while increasing creatinine clearance was also associated with not attaining the target for the whole dosing interval. It is unknown whether inconsistent concentrations have contributed to the lack of effect of combination antimicrobial

\section{Springer}


therapy in severe gram-negative infections [13]; however, what is clear from these studies is that the definitions of adequate antimicrobial therapy used in the past decades were clearly not adequate. Whether dose optimization of antibiotics, achieved by continuous infusion and daily therapeutic drug monitoring $[14,15]$, will really improve outcomes in our patients is under investigation.

Once the microbiological results are available and the patient's response is observed, narrowing the antibiotic regimen on the basis of susceptibilities of the identified pathogens should be strongly encouraged to reduce unnecessary antimicrobial exposure and avoid the emergence of resistance at the community level [3, 4]. Garnacho-Montero et al. assessed the impact of deescalation in 219 (34.9\%) of the 628 patients admitted to the ICU in a single hospital in Spain [16]. De-escalation of empirical broad-spectrum antibiotic therapy most often consisted of switching to combinations of third-generation cephalosporins or cefepime plus a fluoroquinolone or a glycopeptide followed by a carbapenem plus a glycopeptide. They found that de-escalation was safe; however, what was less expected is that this strategy was even associated with a lower in-hospital and 90-day mortality. Leone et al. conducted a multicenter non-blinded randomized non-inferiority trial in 116 patients with severe sepsis [17]. Combination therapy most often consisted of the addition of an aminoglycoside. They found that de-escalation did not worsen patient outcomes; however, this strategy was associated with more superinfections. Finally, Mokart et al. performed an observational study on de-escalation in a population which is traditionally considered at high risk of mortality, namely neutropenic patients with severe sepsis [18]. They included 101 patients in whom deescalation was performed in $44 \%$ and found no excess in mortality in multivariate analysis. They concluded that de-escalation is often performed in this population and that it does not appear to have any impact on outcomes. Similar to studies on combination antimicrobial treatment, these reports mainly indicate that largescale multicentric randomized controlled trials should be conducted to assess the impact of de-escalation on the patient's outcome and concomitantly on resistance patterns at the community level. De-escalation should mainly be based on antibiotic susceptibility testing since this approach was found to be associated with a lower mortality in patients with bacteremia, severe sepsis, or ventilator-associated pneumonia in a recent metaanalysis [19]. Thanks to rapid diagnostic systems it will be possible to dramatically reduce the delay in microbiological identification of pathogens and susceptibility testing in the near future [20].

\begin{abstract}
Author details
${ }^{1}$ Department of Intensive Care, Ghent University Hospital, Ghent, Belgium. ${ }^{2}$ Northern Clinical School Intensive Care Research Unit, University of Sydney, Sydney 2006, Australia. ${ }^{3}$ IAME, UMR 1137, INSERM, Université Paris Diderot, Sorbonne Paris Cité, AP-HP, Service de Réanimation Médicale et des Maladies Infectieuses, Hôpital Bichat, AP-HP, Paris, France.
\end{abstract}

Received: 23 August 2016 Accepted: 20 September 2016

Published online: 29 September 2016

\section{References}

1. Carlet J (2014) Ten tips on how to win the war against resistance to antibiotics. Intensive Care Med 41:899-901

2. Bassetti M, Nicolau DP, Calandra T (2014) What's new in antimicrobial use and resistance in critically ill patients. Intensive Care Med 40:422-426

3. Bassetti M, De Waele JJ, Eggimann P, Garnacho-Montero J, Kahlmeter G, Menichetti F, Nicolau DP, Paiva JA, Tumbarello M, Welte T, Wilcox M, Zahar JR, Poulakou G (2015) Preventive and therapeutic strategies in critically ill patients with highly resistant bacteria. Intensive Care Med 41:776-795

4. Kollef MH (2014) What can be expected from antimicrobial de-escalation in the critically ill? Intensive Care Med 40:92-95

5. Paul M, Lador A, Grozinsky-Glasberg Leibovici L (2014) Beta lactam antibiotic monotherapy versus beta lactam-aminoglycoside antibiotic combination therapy for sepsis. Cochrane Database Syst Rev 7(1):CD003344

6. Paul M, Dickstein Y, Schlesinger A, Grozinsky-Glasberg S, Soares-Weiser L, Leibovici L (2013) Beta-lactam versus beta-lactam-aminoglycoside combination therapy in cancer patients with neutropenia. Cochrane Database Syst Rev 29(6):CD003038

7. Bretonnière $C$, Leone $M$, Milési $C$, Allaouchiche $B$, Armand-Lefevre $L$, Baldesi O, Bouadma L, Decré D, Figueiredo S, Gauzit R, Joram N, Jung B, Lasocki S, Lepape A, Lesage F, Pajot O, Phiippart F, Souweine B, Tattevin P, Timsit JF, Vialet R, Zahar JR, Misset B, Bedos JP (2015) Strategies to reduce curative antibiotic therapy in intensive care units (adult and paediatric). Intensive Care Med 41:1181-1196

8. de Lastours V, Chau F, Roy C, Larroque B, Fantin B (2014) Emergence of quinolone resistance in the microbiota of hospitalized patients treated or not with a fluoroquinolone. J Antimicrob Chemother 69:3393-3400

9. Haverkate MR, Derde LPG, Brun-Buisson C, Bonten MJM, Bootsma MCJ (2014) Duration of colonization with antimicrobial-resistant bacteria after ICU discharge. Intensive Care Med 40:564-571

10. De Montmollin E, Bouadma L, Gault N, Mourvillier B, Mariotte E, Chemam S, Massias L, Papy E, Tubach F, Wolff M, Sonneville R (2014) Predictors of insufficient amikacin peak concentration in critically ill patients receiving a 25 mg/kg total body weight regimen. Intensive Care Med 40:998-1005

11. Roberts JA, Paul SK, Akova M, Bassetti M, De Waele JJ, Dimopoulos G, Kaukonen KM, Koulenti D, Martin C, Montravers P, Rello J, Rhodes A, Starr T, Wallis SC, Lipman J (2014) DALI: defining antibiotic levels in intensive care unit patients: are current beta-lactam antibiotic doses sufficient for critically ill patients? Clin Infect Dis 58:1072-1083

12. De Waele JJ, Lipman J, Akova M, Bassetti M, Dimopoulos G, Kaukonen M, Koulenti D, Martin C, Montravers P, Rello J, Rhodes A, Udy AA, Starr T, Wallis SC, Roberts JA (2014) Risk factors for target non-attainment during empirical treatment with $\beta$-lactam antibiotics in critically patients. Intensive Care Med 40:1340-1351

13. Matthaiou DK, De Waele J, Dimopoulos G (2014) What is new in the use of aminoglycosides in critically ill patients? Intensive Care Med 40:1553-1555

14. De Waele JJ, Carrette S, Carlier M, Stove V, Boelens J, Claeys G, LerouxRoels I, Hoste E, Depuydt P, Decruyenaere J, Verstraete AG (2014) Therapeutic drug monitoring-based dose optimization of piperacillin and meropenem: a randomized controlled trial. Intensive Care Med 40:380-387

15. De Pascale G, Fortuna S, Tumbarello M, Cutuli SL, Vallecoccia MS, Spanu T, Bello G, Montini L, Pennisi MA, Navarra P, Antonelli M (2015) Linezolid plasma and intrapulmonary concentrations in critically ill obese patients with ventilator-associated pneumonia: intermittent vs continuous administration. Intensive Care Med 41:103-110 
16. Garnacho-Montero J, Gutiérrez-Pizarraya A, Escoresca-Ortega A, Corcia-Palomo Y, Fernandez-Delgado E, Herrera-Melero I, Ortiz-Leyba C, Marquez-Vacaro JA (2014) De-escalation of empirical therapy is associated with lower mortality in patients with severe sepsis and septic shock. Intensive Care Med 40:32-40

17. Leone $M$, Bechis $C$, Baumstarck K, Lefrant JY, Albanèse J, Jaber S, Lepape A, Constantin JM, Papazian L, Bruder N, Allaouchiche B, Bézulier K, Antonini F, Textoris J, Martin C, for the AZUREA Network Investigators (2014) De-escalation versus continuation of empirical antimicrobial treatment in severe sepsis: a multicenter non-blinded randomized noninferiority trial. Intensive Care Med 40:1399-1408
18. Mokart D, Slehofer G, Lambert J, Sannini A, Chow-Chine L, Brun JP, Berger P, Duran S, Faucher M, Blache JL, Saillard C, Vey N, Leone M (2014) Deescalation of antimicrobial treatment in neutropenic patients with severe sepsis: results from an observational study. Intensive Care Med 40:41-49

19. Paul M, Dickstein Y, Raz-Pasteur A (2016) Antibiotic de-escalation for bloodstream infections and pneumonia: systematic review and meta-analysis. Clin Microbiol Inf: S1 198-743X(16)30175-6. doi:10.1016/j.cmi.2016.05.023

20. Banerjee R, Teng CB, Cunningham SA, Ihde SM, Steckelberg JM, Moriarty JP, Shah ND, Mandrekar JN, Patel R (2015) Randomized trial of rapid multiplex polymerase chain reaction-based blood culture identification and susceptibility testing. Clin Infect Dis 61:1071-1080 